\title{
Speak up!
}

Shaun Sellars continues his series on ethical dilemmas in dentistry

which appears in every second issue of the BDJ.

The General Dental Council (GDC) report that they received 100 whistleblowing disclosures in the financial year April 2020-2021. This is 'a higher number of disclosures in comparison to the size of the register' in contrast to some of the other healthcare regulators and can, in part at least, be explained by 'alternative disclosure routes [being] less present in dentistry', which lands these complaints at the door of the GDC. It is further exacerbated by dentistry predominantly being performed in a 'primary care setting and outside the more robust clinical governance frameworks that characterise some other forms of healthcare. ${ }^{1}$

The underlying culture throughout much of the profession and the weaponisation of GDC referrals has compounded the whistleblowing issue. All too often, we hear of dentists reporting colleagues due to personal or business grievances disguised as patient protection. The GDC then has the challenge of separating vexatious complaints from those arising from genuine concerns. ${ }^{2}$

Any solution to this problem is complex and must involve an independent intermediary process; for example, utilising Freedom to Speak Up (FtSU) Guardians.
FtSU Guardians are there not only for whistleblowing cases but also to enable others to speak up about anything that hinders good care. That may be about preventing harm, but equally could be regarding ways to improve an already good working situation.

In larger organisations, such as NHS

Trusts and dental corporate bodies, the introduction of FtSU Guardians should be relatively simple. It is straightforward enough to find someone, or several people, who are far enough removed from the majority of the workforce to be independent enough to carry out FtSU tasks. Still, in smaller practices, this may be more difficult.

As anyone who's worked in a small practice will know, cliques and power struggles can stifle productivity and job satisfaction. Most of us will have stories of the associate who thinks they're the boss or the practice manager who thinks they rule the roost. Encouraging people to speak up in these situations is made more challenging by the unwritten hierarchy of power within the practice and the difficulty of finding someone who colleagues can trust to speak up to. For me, flattening that hierarchy of rule and reducing the discrepancy in power between work colleagues is essential in practice.

However, the historical power structures

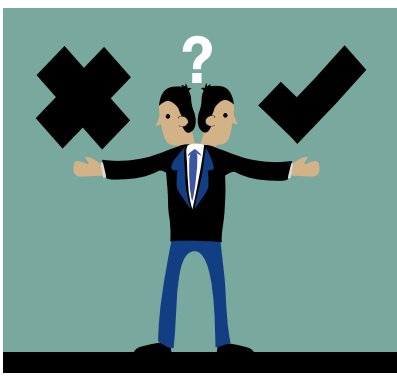

present in dentistry are hard to overcome. Instead, consideration may need to be given to external FtSU services, supported through Local Dental Committees or similar organisations.

But essentially, dentistry must change to cultivate a culture that is willing to listen up to concerns, and follow up with investigations and changes as appropriate. However, culture change is slow and can be unpredictable. We need to replace the superiority shown by many in a position of influence in the profession with introspection, humility and willingness to improve. In many ways, this is already happening. For dentistry to move towards a progressive, inclusive future, we need leaders who can take dentistry into a new era of openness and collaboration. We all need to speak up for dentistry.

\section{References}

1. Healthcare Professional Regulators. Whistleblowing disclosures report. 2021. Available at: https://www. gdc-uk.org/DownloadHelper.aspx?doclD=f02d23af9529-4347-b73b-8d49993f1bc6 (accessed September 2021)

2. D'Cruz L. Blue on blue. Br Dent J 2020; 228: 13-14.

\section{BDA AGM}

The BDA Northern Ireland Branch AGM will be held on Tuesday 9 November 2021 at 19:00 online (GoToMeeting).

All BDA members are welcome. For further information and to book please visit www.bda.org/bse.

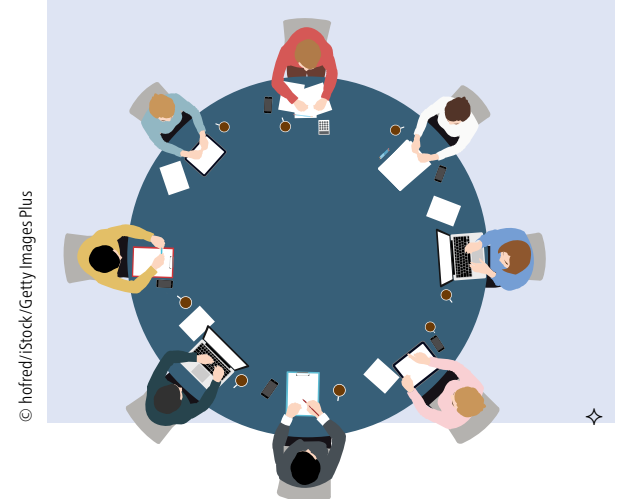

\section{BDA Library now open!}

The BDA Library is now open to visitors again from 10:30 to 15:30 every Wednesday and Thursday. You will need to make an appointment if you wish to spend more than a few minutes browsing in the library.

You may browse, return and collect items without making an appointment.

Find more details on the library homepage www.bda.org/library. The library staff look forward to welcoming you back.

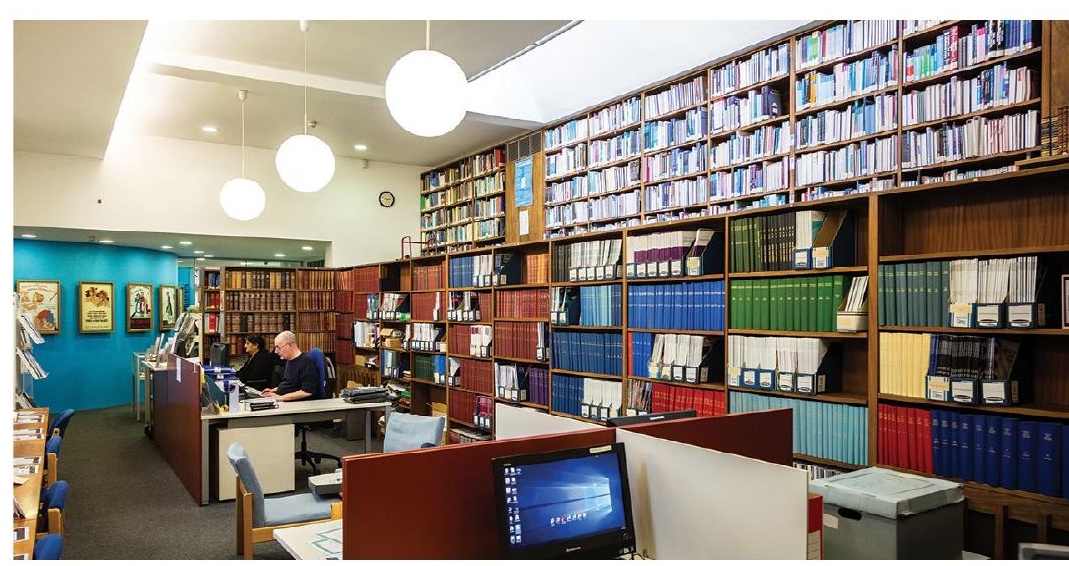

